\title{
Analysis the Islanding Mode of Combined Operation of DG and UPQC in Unbalanced Distribution System
}

\author{
S.M.Ale-Emran, H.R.Baghaee, M.Abedi, G.B.Gharehpetian, \\ Electrical Engineering Department, Amirkabir University of Technology, Tehran, Iran \\ aleemran2000@gmail.com
}

\begin{abstract}
The proposed system consists of a series inverter, a shunt inverter, and a Distributed Generation (DG) connected in the dc link. It focuses on improving the power quality and ensuring the continuity of the electric power supply. The function of the scheme has been investigated in islanding mode which is a challenging mode of UPQC. The formulation of the proposed control scheme which is based on the instantaneous power theory is described. The proposed system can improve the power quality at the point of installation on power distribution systems or industrial power systems. Compensation of reactive power at the Point of Common Coupling (PCC) is examined. The effectiveness of the proposed scheme has been verified by simulation.
\end{abstract}

\section{Key words}

Distributed Generation, Distribution System, Power Quality, UPQC

\section{Introduction}

Power quality and power system deregulation have become very important concerns for utility, facility, and consulting engineers in recent years.

The increasing applications of electronic equipment and increasingly development of nonlinear loads in distribution system is deteriorating power quality and causing disturbance in the operation of many sensitive loads. The high power quality of the power results in a direct economic impact on utilities, their customers and suppliers. Custom power devices, including power electronic interface, can be an effective solution for the increasing power quality problems. The devices can provide fast response and flexible compensation. DVR, DSTATCOM, and series and/or shunt connected active filter are representative custom power devices. Usually, series and shunt inverter integrated device is called Unified Power Quality Conditioner (UPQC). The UPQC is one of the most versatile devices which has the prominent capability of improving the quality of voltage and current at the point of installation in power distribution system or industrial power systems. Therefore, UPQC is expected to be one of the most powerful solutions for the load which is considered as very important or sensitive to supply voltage disturbances [1]-[11].

The interest in distributed generation (DG) has been increasing rapidly, too. The worldwide concern about environmental pollution and the possible energy shortage has led to increasing interest in generation of renewable electrical energy. DG can solve many typical problems, such as energy security problem [12]-[14]. Clean and convenient energy is becoming more and more attractive in industrial and commercial applications at a variety of power levels. DG can yield economic benefits, such as reducing the transmission line losses and the cost of highvoltage equipment insulation. However, a small DG has some significant power quality problems. Therefore, a combined DG and UPQC could mitigate power quality disturbances [15]-[16].

There are several DGs that can be used in this combination such as, photovoltaic systems, Fuel cells, Micro-turbines, Wind turbine and etc. wind power generation has been significantly developed during the last decades and is one of the forms of power generation of fastest growth in the world [17]. Wind energy generation is one way of electrical generation from renewable sources that uses wind turbine generators (WTGs) to convert the energy contained in flowing wind into electrical energy. Wind power has become the fastest growing energy source in the world and the leading source among various renewable energy sources in the power industry.

Fuel cells are static energy conversion devices that convert the chemical energy of fuel into electrical energy directly. With clean operating environment and high energy conversion efficiency, fuel cell is getting more and more attention, especially for the stationary power application. Such an application, either delivering electricity with utility intertie or directly supplying to residential area as a standalone power source, can be used for future distributed generation systems [18]. Photovoltaic power is an established technology and has recently experienced rapid growth over the last ten years. Photovoltaic (PV) energy has great potential to supply energy with minimum impact on the environment, since it is clean and pollution free. One way of using photovoltaic energy is in a distributed energy system as a peaking power source. On the other hand, strict regulations have been applied to the equipment connected to the utility lines. Some of these regulations relate to harmonic distortion and power factor. Photovoltaic cells are the key component in most photovoltaic power systems, but their performance is still subpar, so future work is needed to 
improve their performance and optimize the interactions between the cells and other components [19].

Each of above mentioned DGs could be used for the following proposed system.

\section{The Configuration of Proposed System}

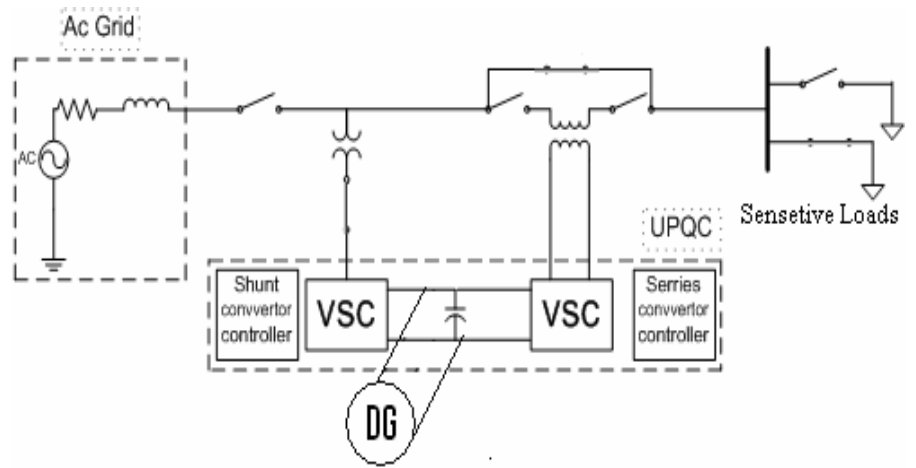

Fig.1: Combined operation of UPQC and DG in Islanding mode

The control of the proposed configuration has two operating modes: paralleling mode and islanding mode. Each control mode is determined by the state of Solid State Breaker (SSB). Fig. 1 shows the combined operation of UPQC and DG in islanding mode. This mode is the most challenging situations for power quality issues. If the grid voltage drops below the certain threshold voltage level beyond the certain fixed duration, SSB should disconnect customer's network from the utility lines. Then proposed configuration changes its operating mode from paralleling mode to islanding mode. Furthermore, if there are several DGs in the islanded network, all of the DG units should have proper control strategy to share loads. In this paper, an interconnected DG using UPQC in unbalanced distribution system is studied in islanding mode. This paper aims at proper control of system to improve power factor, voltage regulation and mitigate other power quality problems.

\section{Control Scheme of the Proposed System}

The instantaneous power theory is used to control the proposed system. This scheme includes DG to deliver its power to loads and maintaining DC link voltage as well as other condition tasks. The theory is based on converting three axis parameters into two axes by defining well-known transfer matrix.

For example using the matrix for three phase voltage signals leads to $V_{\alpha}, V_{\beta}, V_{0}$. And finally, instantaneous active and reactive power, results from:

$$
\left[\begin{array}{c}
p_{0} \\
p \\
q
\end{array}\right]=\left[\begin{array}{ccc}
V_{0} & 0 & 0 \\
0 & V_{\alpha} & V_{\beta} \\
0 & -V_{\beta} & V_{\alpha}
\end{array}\right]\left[\begin{array}{l}
i_{0} \\
i_{\alpha} \\
i_{\beta}
\end{array}\right]
$$

Where $V_{\alpha}, V_{\beta}, V_{0}$ and $i_{\alpha}, i_{\beta}, i_{0}$ are the $\alpha-\beta-0$ transformation of $V_{a}, V_{b}, V_{c}$ and $i_{a}, i_{b}, i_{c}$ respectively. Then the active and reactive instantaneous power can be decomposed by DC component and AC harmonic components, which consist of negative sequence component and harmonic component [20]-[22].

$$
\left\{\begin{array}{c}
p=\bar{p}+\tilde{p} \\
q=\bar{q}+\tilde{q} \\
p_{0}=\bar{p}_{0}+\tilde{p}_{0}
\end{array}\right.
$$

Because the zero sequence power $p_{0}$ never produces a constant DC component without its associated AC component, the proposed system should compensate fully power $p_{0}$ when it is applied to a three-phase four-wire networks and the additional active power component drawn from supply needs to be injected:

$$
\left\{\begin{array}{c}
p_{\text {control }}=p_{0}+\tilde{p} \\
q_{\text {control }}=\bar{q}+\tilde{q}
\end{array}\right.
$$

Where:

$p_{0}$ is zero sequence of active power.

$\tilde{p}_{\text {is negative sequence and AC harmonic component }}$ of active power.

$\bar{q}$ is direct component of reactive power.

$\tilde{q}_{\text {is alternative component of reactive power }}$ associated to the harmonic reactive component.

If shunt inverter is used simultaneously for reactive, negative and harmonic component compensation, the $\alpha-\beta$ axis current reference is given by the following equation:

$$
\begin{gathered}
{\left[\begin{array}{l}
i_{c \alpha}^{*} \\
i_{c \beta}^{*}
\end{array}\right]=\frac{1}{v_{\alpha}^{2}+v_{\beta}^{2}}\left[\begin{array}{ll}
v_{\alpha} & -v_{\beta} \\
v_{\beta} & v_{\alpha}
\end{array}\right]\left[\begin{array}{l}
-p_{\text {control }} \\
-q_{\text {control }}
\end{array}\right]} \\
{\left[\begin{array}{l}
i_{c a}^{*} \\
i_{c b}^{*} \\
i_{c c}^{*}
\end{array}\right]=[C]^{T}\left[\begin{array}{c}
i_{0} \\
i_{c \alpha}^{*} \\
i_{c \beta}^{*}
\end{array}\right]}
\end{gathered}
$$

Where

$$
[C]^{T}=[C]^{-1}=\sqrt{2} / 3\left[\begin{array}{ccc}
1 / \sqrt{2} & 1 & 0 \\
1 / \sqrt{2} & -1 / 2 & \sqrt{3} / 2 \\
1 / \sqrt{2} & -1 / 2 & -\sqrt{3} / 2
\end{array}\right]
$$

When the series converter of the proposed configuration is used simultaneously for reactive, negative and harmonic compensation, the $\alpha-\beta$ axis voltage reference is given by equation (6).

$\left[\begin{array}{c}v_{c \alpha}^{*} \\ v_{c \beta}^{*}\end{array}\right]=\frac{1}{i_{\alpha}^{2}+i_{\beta}^{2}}\left[\begin{array}{cc}i_{\alpha} & -i_{\beta} \\ i_{\beta} & i_{\alpha}\end{array}\right]\left[\begin{array}{l}-p_{\text {control }} \\ -q_{\text {control }}\end{array}\right]$ 
$\left[\begin{array}{c}V_{c a}^{*} \\ V_{c b}^{*} \\ V_{c c}^{*}\end{array}\right]=[C]^{T}\left[\begin{array}{c}V_{0} \\ V_{c \alpha}^{*} \\ V_{c \beta}^{*}\end{array}\right]$

When the shunt converter of the proposed configuration is used for the charge control of battery, the active reactive power control is becoming the main issue, and the proposed system still satisfy the compensation demand of load such as negative and harmonic compensation. Then the $\alpha-\beta$ axis current reference is given by equation (8).

$\left[\begin{array}{c}i_{c \alpha}^{*} \\ i_{c \beta}^{*}\end{array}\right]=\frac{1}{v_{\alpha}^{2}+v_{\beta}^{2}}\left[\begin{array}{cc}v_{\alpha} & -v_{\beta} \\ v_{\beta} & v_{\alpha}\end{array}\right]\left[\begin{array}{c}p_{\text {control }}+p_{D G} \\ q_{\text {control }}\end{array}\right]$

Where $p_{D G}$ is the DG power delivered to local loads by shunt converter. It should be noted that, it is so difficult to compensate reactive power and harmonic current using series converter only and because the signals from converter output terminals must be passed through the filters, the filter design strongly depends on the system parameters like load size and transformer turns ratio.

\section{Simulation Results}

The operation of the proposed configuration is evaluated by computer simulations using PSCAD/EMTDC.

Using these simulations, it is possible to evaluate the performance of the proposed scheme in compensating the reactive power at the Point of Common Coupling(PCC) under sudden load changing condition and unbalanced condition, while retain the active power at its reference value.

Fig. 2 shows the dynamic response of the proposed scheme when high load is switched two times, first at $\mathrm{t}=$ $0.2 \mathrm{sec}$, and then removed at $\mathrm{t}=0.3 \mathrm{sec}$ and the other time at $\mathrm{t}=0.4 \mathrm{sec}$ and then removed at $\mathrm{t}=0.55 \mathrm{sec}$. It is clear that the proposed scheme succeeded in tracking and compensating the reactive power demand of the load with fast dynamics and with minimum overshoot. The waveform of the figure 2-c shows that the active power supplied from proposed configuration is almost constant and equal to its input command value.

Considering the figures 2-b and 2-c it can be seen that the control of active and reactive power is decoupled. In addition, last waveform (figure 2-d) shows the effect of the scheme on the voltage at the PCC. This scheme improves the per unit voltage at the PCC.

Fig. 2-e shows the DC voltage variation of the DC bus. During the load disturbance, the shunt inverter only provides power to the load. The voltage of DC bus maintains a constant value by the support of DG unit during the load disturbance. Thus, it shows the stability and the reliability of the proposed system.

These simulation results of the proposed system validate the improvement of the power reliability and quality under the load disturbances.

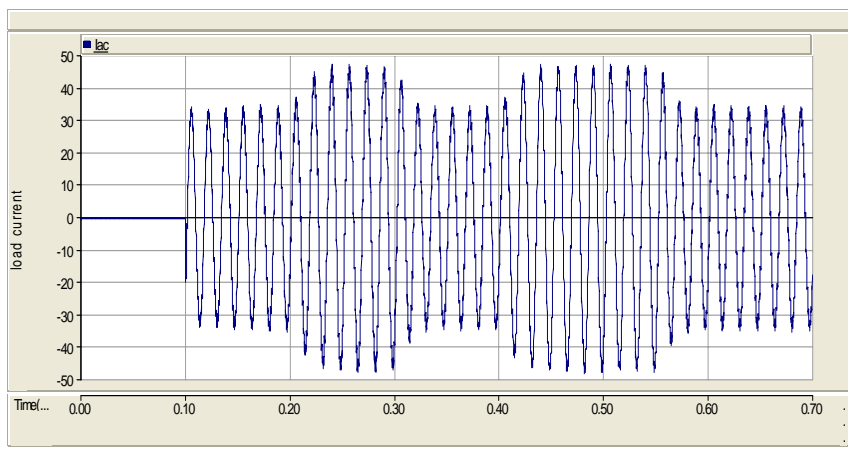

(a)

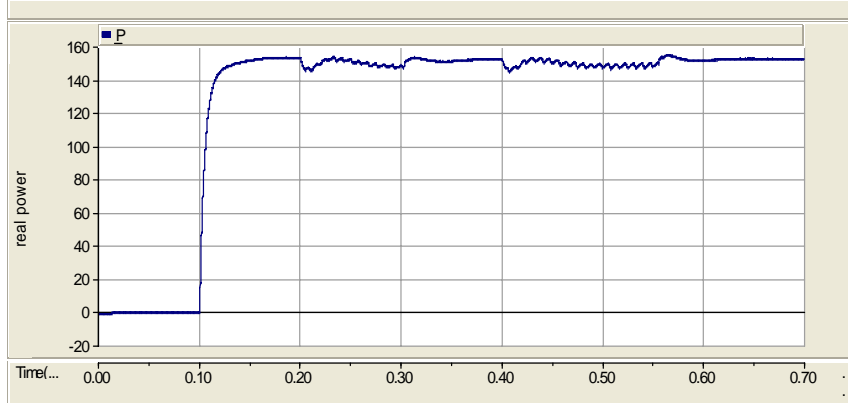

(b)

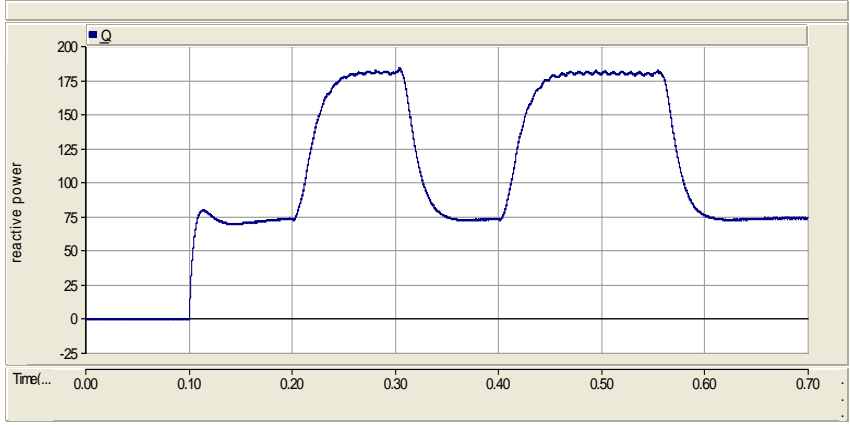

(c)

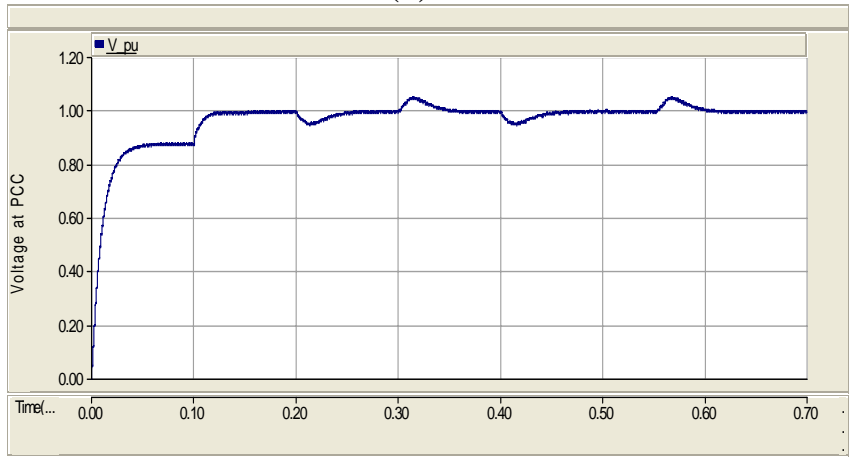

(d)

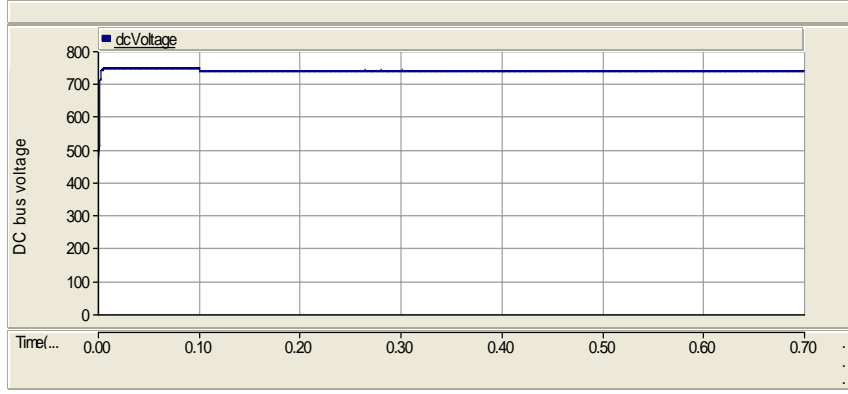

(e)

Fig. 2: Reactive power compensation corresponding to sudden load change. (a) Load Current (Amper), (b) Compensated kVar, (c) kWatt supplied by UPQC, (d) Voltage at PCC (per unit), (e) DC bus voltage(Volt) 


\section{Conclosion}

The system proposed in this paper has the functions of improving power quality, and ensuring the continuity of electricity supply. It can control power to the grid and power quality in islanding operation mode and keep the load voltage in constant and follow up the load power variation even in unbalanced distribution system. The advantages and flexibility of the proposed configuration are described. In addition, the control schemes of the proposed system and its numerical formulations are presented. The simulation results based on PSCAD/EMTDC software show the effectiveness of the suggested control systems in islanding operation mode.

\section{Refrences}

[1] IEEE Std 1159 - IEEE Reconmended Pradce for monitoring Electnc Power Quality. June 1995

[2] Mehdi Forghani Saeed Afsharnia, "Online Wavelet Transform-Based Control Strategy for UPQC Control System”, "Power Delivery, IEEE Transactions. Jan. 2007, vol.22, pp. 481-491

[3] K. Gokhale, A. Kawamura, and R. Hoft, "Deadbeat microprocessor control of PWM inverter for sinusoidal output waveform synthesis,”IEEE Trans. Ind. Appl., vol. IA-23, no. 5, pp. 901-910, Sep./Oct. 1987.

[4] A. A. Girgis and F. Ham, "A quantitative study of pitfall in FFT,” IEEE Trans. Electron. Syst., vol. ES-16, no. 4, pp. 434439, Jul. 1980.

[5] Aredes. M, K. Hemnn. and E.H. Watanabe. "An Universal Active Power Line Conditioner," IEEE Trans. on Power Delivery, vol.13, no.2. April 1998, pp545-551.

[6] H. Akagi. Y. Kanazawa, and A. Nabae. "Instantaneous Reactive Power Compensators Comprising Switching Devices without Energy Storage Components.” IEEE Trans. on Industry Application. vol. IA-20. no.3, May/June 1984, pp625-630.

[7] F. V. Edwards, G. J. W. Dudgeon, J. R. McDonald and W. E. Leithead, "Dynamics of distribution network with Distributed Generation”, IEEE/ PES summer meeting 2000, Vol. 2.

[8] L. F C. Monteiro, M. Aredes and J. A. Moor Neto, "A control strategy for unified power quality conditioner", Industrial Electronics. ISIE '03. IEEE International Symposium on, vol.1, pp.9- 11, June.2003.

[9] M. T. Haque, T. Ise, S. H. Hosseini, "A novel control strategy for unified power quality conditioner (UPQC)", Power Electronics Specialists Conference. Vol.1,pp.94-98, June2002.

[10] V. Khadkikar, P. Agarwal, A. Chandra, A. 0. Barry and T. D. Nguyen, "A simple new control technique for unified power quality conditioner (UPQC)", Harmonics and Quality of Power. pp.289-293, Sept. 2004.

[11] Experimental Investigation of a Single-Phase UPQC With Minimum VA Loading Yashomani Y. Kolhatkar Shyama P. Das Indian Inst. of Technol., Kanpur; Power Delivery, IEEE Transactions on Jan.2007. Volume: 22, Issue:1 On page(s): 373-380

[12] M. W. Davis, "Distributed resource electric power systems offer significant advantages over central station generation and T\&D power systems," in Proc. Power Engineering Soc. Summer Meeting, vol. 1, 2002, pp. 61-69.

[13] P. P. Barker and R.W. de Mello, "Determining the impact of distributed generation on power systems: Part1-Radial distribution systems,” in Proc. IEEE Power Engineering Soc. Summer Meeting, vol. 3, 2000, pp. 1645-1656.

[14] T. Ackerman, G. Anderson, and L. Soder, "Electricity market regulations and their impact on distributed network," in
Proc. Electric Utility Deregulation Restructuring Power Technologies, 2000, pp. 608-613.

[15] B. Han, B. Bae, H. Kim, and S. Baek, Combined Operation of Unified Power-Quality Conditioner with Distributed Generation,

IEEE Transaction on Power Delivery, Vol. 21, No. 1, January 2006

[16] Sung-Woo Park, 11-Yop Chung, Joon-Ho Choi,Seung-I1 Moon, and Jae-Eon Kim ,Control Schemes of the InverterInterfaced Multi-functional Dispersed Generation

[17]German C. Tarnowski and Romeu Reginatto, "Adding Active Power Regulation to Wind Farms with Variable Speed Induction Generators" IEEE 2007.

[18] Changrong Liu and Jih-Sheng Lai, "Low Frequency Current Ripple Reduction Technique With Active Control in a Fuel Cell Power System With Inverter Load" IEEE Transactions on Power Electronics, Vol. 22, No. 4, July 2007.

[19] Weidong Xiao, Nathan Ozog and William G. Dunford," Topology Study of Photovoltaic Interface for Maximum Power Point Tracking " IEEE Transactions on Industrial Electronics, Vol. 54, No. 3, June 2007.

[20] Zhan Changjiang Wong Manchung Han Yu Han Yingduo Zhao Liangbing,"Universal custom power conditioner (UCPC) in distribution networks”, “ Power Electronics and Drive Systems, 1999. PEDS '99. Proceedings of the IEEE 1999 International Conference”, vol. 2, pp. 1067-1072 [21] Salehi, V. Kahrobaee, S. Afsharnia, S.,"Power Flow Control and Power Quality Improvement of Wind Turbine Using Universal Custom Power Conditioner". "Industrial Electronics, July 2006 IEEE International Symposium”,vol. 3, pp.1888-1892

[22] Changjiang Zhan Ramachandaramurthy, V.K. Arulampalam, A. Fitzer, C. Barnes, M. Jenkins, N. ,"Universal custom power conditioner (UCPC) with integrated control" ," Power Engineering Society Winter Meeting, 2001. IEEE” vol.3, pp. 1039-1044 